\title{
Making Friends in Violent Neighborhoods: Strategies among Elementary School Children
}

\author{
Anjanette M. Chan Tack, ${ }^{a}$ Mario L. Small ${ }^{b}$
}

\author{
a) University of Chicago; b) Harvard University
}

\begin{abstract}
While many studies have examined friendship formation among children in conventional contexts, comparatively fewer have examined how the process is shaped by neighborhood violence. The literature on violence and gangs has identified coping strategies that likely affect friendships, but most children in violent neighborhoods are not gang members, and not all friendship relations involve gangs. We examine the friendship-formation process based on in-depth interviews with 72 students, parents, and teachers in two elementary schools in violent Chicago neighborhoods. All students were African American boys and girls ages 11 to 15 . We find that while conventional studies depict friendship formation among children as largely affective in nature, the process among the students we observed was, instead, primarily strategic. The children's strategies were not singular but heterogeneous and malleable in nature. We identify and document five distinct strategies: protection seeking, avoidance, testing, cultivating questioners, and kin reliance. Girls were as affected as boys were, and they also reported additional preoccupations associated with sexual violence. We discuss implications for theories of friendship formation, violence, and neighborhood effects.
\end{abstract}

Keywords: friendship formation; networks; violence; neighborhood effects; child development

Citation: Chan Tack, Anjanette M., and Mario L. Small. 2017. "Making Friends in Violent Neighborhoods: Strategies among Elementary School Children." Sociological Science 4: 224-248.

Received: January 12, 2017

Accepted: February 8, 2017

Published: March 15, 2017

Editor(s): Jesper B. Sørensen, Gabriel Rossman

DOI: $10.15195 / \mathrm{v} 4 . \mathrm{a} 10$

Copyright: (C) 2017 The Author(s). This open-access article has been published under a Creative Commons Attribution License, which allows unrestricted use, distribution and reproduction, in any form, as long as the original author and source have been credited. (0)(1)

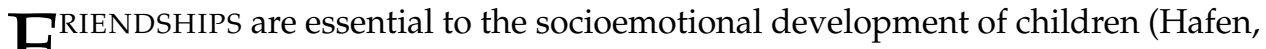
1 Laurson, and DeLay 2012). A large body of psychological literature has found that failure to form successful, enriching friendships during childhood can lead to maladjustment, low educational attainment, and criminal behavior in adulthood (Parker and Asher 1987). In fact, researchers have argued that the friendship formation practices learned during childhood shape people's ability to maintain stable relationships as adults (Furman et al. 2002; Giordano 2003). Not surprisingly, understanding how children and adolescents form friendships has motivated a large body of work (e.g., Hallinan 1979; Parker and Seal 1996; Lubbers and Snijders 2007).

Although this work has examined the process across a variety of conventional contexts, there has been comparatively little research on how neighborhood violence affects how children form friends (but see Anderson 1990; Jones 2004, 2009; Harding $2009,2010)$. This gap in the literature is notable given the copious research on violence in urban areas and on the negative consequences for children of living in disadvantaged neighborhoods (Sampson, Morenoff, and Gannon-Rowley 2002; Chetty, Hendren, and Katz 2016). As we discuss below, a large literature spanning several decades has examined violence, friendship, and loyalty in gangs (Thrasher [1927] 2013; Sanchez Jankowski 1991; Venkatesh 2000). This work has shown convincingly, among other things, that many adolescents join gangs for protection. However, as a recent National Institute of Justice report put it, "most youth-even those most at risk, living in the most distressed urban communities-do not join a 
gang" (Ritter, Simon, and Mahendra 2014:3; italics in original). In fact, Pyrooz and Sweeten (2015), based on representative data, estimated a national juvenile gang membership rate of only 2 percent in 2010. Moreover, because much gang research focuses on delinquent behavior and on older, adolescent males, it has shed less light on how younger, nondelinquent adolescent boys and girls make friends in response to violent neighborhoods (Peterson 2011; Miller 2000).

The question becomes particularly important given the persistently high levels of violence that some children experience. Though rates of violent crime are historically low in most cities, they remain persistently high - and have in fact risen in recent years-in several major cities, such as Baltimore and Chicago. In 2015, Baltimore experienced the highest homicide rate in its history (Rector 2016). In 2016, Chicago, the site of our study, experienced 750 murders, the largest number since 1997 (Bostman and Smith 2016). Violent crime rates in Chicago have been persistently high for some time. An earlier survey of more than 500 children in three elementary schools on Chicago's South Side found that 26 percent of elementary school children had witnessed a shooting, 30 percent had witnessed a stabbing, and 78 percent had witnessed a beating (Bell and Jenkins 1993). In fact, studies using nationally representative data have shown that black and Latino children (who are more likely to live in urban contexts) are twice as likely as white children to be assaulted with a weapon, to be assaulted by multiple assailants, and to be injured during assault. Furthermore, black children are three times more likely to be exposed to shootings and twenty times more likely to witness a murder than white children (Finkelhor et al. 2005; see also Finkelhor et al. 2011, 2014). Using Add Health data, Harding (2010:29) reports that children in communities where poverty rates exceed 40 percent are more than three times as likely to feel unsafe as those in nonpoor neighborhoods.

In what follows, we examine how children think about friendship formation based on in-depth interviews of middle schoolers in violent, high-poverty Chicago neighborhoods. We find that the children rarely exhibited the affective orientation reported in the literature on friendship formation among children, such as a primary orientation toward homophily in hobbies; instead, they adopted an unusually strategic and instrumental approach to friendship, one explicitly governed by the need to manage the threat of violence. While we confirm the finding in gang research that some children strategically befriend peers who can provide protection, we also find that many children do the opposite, studiously avoiding making friends with "street oriented" peers. In fact, many children adopt not one but multiple strategies, resulting in a heterogeneous stance toward friendship formation. That is, we find that a consequence of exposure to neighborhood violence appears to be an approach to friendship formation that is unusually strategic, highly malleable, and notably heterogeneous. We identify and document the presence of five distinct friendship formation strategies: (1) protection seeking, (2) avoidance, (3) testing, (4) cultivating questioners, and (5) kin reliance. We discuss the implications of our findings for research on friendship formation, violence, and neighborhood effects. 


\section{Literature}

\section{Friendship Formation among Children}

The literature on friendship formation, from Lazarsfeld and Merton's (1954) work on the friendship process to the recent work on structural constraints on friend selection (Moody 2001), is diverse. Because forming friends depends on the decisions that individuals make within structural constraints, researchers have adopted many analytical perspectives. They have focused on individual factors such as race, gender, and class (Eder and Hallinan 1978; Tuma and Hallinan 1979; Haselager et al. 1998; Moody 2001; Vaquera and Kao 2008; Crosnoe, Frank, and Mueller 2008; Rude and Herda 2010 ), on dyadic factors such as homophily or reciprocity (Kandel 1978, Goodreau, Kitts, and Morris 2009), on structural factors such as balance and transitivity (Hallinan and Hutchins 1980; McFarland et al. 2014; Rambaran et al. 2015), and on contextual factors such as classroom size and group assignment (Hallinan 1976; Hallinan and Tuma 1978; Frank, Muller, and Mueller 2013; see Verbrugge 1977).

We adopt a perspective focused on the individual, cognizant that it cannot paint a complete picture. Researchers have noted the importance of understanding the role of individual agency in network formation (Emirbayer and Goodwin 1994; Emirbayer and Mische 1998). Individuals must make decisions to engage others in friendship for a friendship to form, and our focus is how children make those decisions.

Some of the most important work on how children make friendship decisions has emerged in developmental psychology. In this work, two broad arguments are common. One, consistent with both traditional and recent network analysis, is the importance of homophily to the process (Merton and Lazarsfeld 1954; McPherson, Smith-Lovin, and Cook 2001). Children have been shown to be drawn to peers with whom they share a broad suite of similarities, including intellectual interests, academic aspirations, hobbies, and physical appearance, as well as personality traits such as humor, politeness, sociability, sensitivity, play style, and play complexity (Kandel 1978; Epstein 1983; Brown 1989; Rubin et al. 1994; Gifford-Smith and Brownell 2003). As children move into adolescence, homophilic matching expands into sports and academic subjects, sociability, aspirations, reputation, and race and gender (Kandel 1978; Epstein 1983; Shrum, Cheek, and Hunter 1988; Brown 1989; Rubin et al. 1994; Hartup 1996).

The second common argument is that friendship formation among children is largely organic, intuitive, and affective rather than instrumental. Children have been found to gravitate toward similar peers through natural attraction and common activities rather than to engage in character assessments of potential friends or carefully weighing the pros and cons of befriending particular peers. In a seminal overview of friendship formation in children, Hartup (1996) summarized the common view well: "Children are not believed to choose friends who are similar to themselves on a rational basis so much as on an experiential one. Accordingly, relationships become established when they 'feel right"' (p. 7). By extension, according to Hartup, homophily arises from affective, not instrumental processes: 
Similar individuals cleave to one another more readily than dissimilar individuals because they are more likely to find common ground in both their activities and their conversations. Antisocial children are thus most likely to make friends with other antisocial children and, in so doing, their common characteristics merge to create a 'dyadic antisocial trait.' Similarly, soccer players or musicians make friends, merge themselves dyadically, and set the stage for becoming even more similar to one another. (Hartup 1996:7)

\section{Friendships and Violence}

Nevertheless, few of these works have studied contexts where neighborhood violence is a primary concern among the studied population (Harding 2009, 2010); such contexts may encourage more instrumental than affective action. In the literature on neighborhood violence, two bodies of work have offered contributions relevant to our question. One has shown that violent crime encourages distrust, withdrawal, and social isolation-in sum, the avoidance of others-thereby undermining friendship formation (McIntyre 1967; Garofalo 1981). Much of this work can be found in ethnographic studies of disadvantaged urban neighborhoods. For example, Anderson $(1990,1999)$ found that neighborhood violence in Philadelphia heightened young men's sensitivity to disrespect, discouraged openness, and contributed to distrust. Similarly, Jones (2004) found that young African American women living in violent neighborhoods in Philadelphia "limit the strength of their social relationships with other young women" to insulate themselves from potential conflicts (p. 58).

A second body of work, focused primarily on gangs, has shown that violent crime encourages young men and women to join gangs for self-protection. Many have reported such findings (Sanchez-Jankowski 1991; Miller 2000; Walker-Barnes and Mason 2001; Flores-Gonzalez 2002; Coughlin and Venkatesh 2003; Ness 2010). Some have reported similar findings among nongang members. Cobbina, Miller, and Brunson (2008) found that young black women in St. Louis relied on male friends and kin for protection when they ventured beyond their neighborhood. Harding (2010:72) found that black adolescent boys in Boston respond to violent, interneighborhood rivalries by fashioning ties with older, nonkin males within their neighborhoods.

Still, both bodies of work have limitations given our question. First, most of the work on self-protection has focused on gangs, and most young people in urban neighborhoods are not gang members. Second, both of these bodies of work have focused on either older adolescents or on adults. The friendship formation practices of children and tweens in violent contexts remains poorly understood (Harding 2010). 


\section{Methods and Setting}

\section{In-Depth Interviews}

We did not begin the project with the intention of studying violence. Instead, the study was an investigation of the relationship between school mobility and how students form network ties. As the students were interviewed about how they formed friendships, they repeatedly and without prompting turned to the topic of violence.

It was possible for us to study friendship formation because of the high mobility of children in Chicago's public schools. In recent years, Chicago's public schools have experienced high rates of student mobility as a result of accelerated school closures and high residential mobility. During the data-collection phase for this study, 7 percent of the children enrolled in Chicago Public Schools had transferred into their schools at some point during the academic year. We interviewed many children who were newly registered at our two schools and who were thus facing the prospect of making new friends. ${ }^{1}$ The two elementary schools, which we call Brown and Goodwin, were thus selected for their contrasting mobility rates and their otherwise similar features: both had student populations that were predominantly black and high poverty, but Brown's school year in-mobility rate was 17.4 percent and Goodwin's was 5.3 percent.

The selection of respondents was explicitly designed to take advantage of the high mobility rates. We did not seek to select a set of children that was representative of Chicago school children, nor do we attempt to make inferences about the distribution of characteristics in the larger population of children based on our findings, an effort for which our data would be inappropriate (Small 2009a). Instead, our article is motivated by the need to bring to light an ambiguity in the literature on the relationship between violence and the process of friendship formation. Our design explicitly called for sampling for range, following a standard practice in qualitative analysis (Weiss 1995; Small 2009a). Because it was important for us to interview children who were both new and not new to the school, we sought sufficient numbers of boys and girls who were newly and not newly registered in each of the two schools. As a result, we have rich interview data on how several different kinds of children in both contexts approach friendship formation. We note that our original expectation-that because of their different mobility rates, there would be major differences between two schools in how children approached friendship formation-was not supported. Instead, children were similar across the schools-in the primacy of violence to their understanding of the friendship process.

Our primary data source is a set of in-depth, open-ended interviews with 44 children in Goodwin and Brown, supplemented by interviews with 16 of their parents and 12 of their teachers and incidental (nonsystematic) field observations, primarily on site at each school and secondarily in the surrounding neighborhood. Interviews ranged from 45 minutes to 1.5 hours, with an average length of one hour. Our principal interviewees were children in sixth, seventh, and eighth grade, with ages ranging from 11 to 15 and an average age of 13 . The fieldwork and interviews were conducted by two researchers, one at each school. The principal 
interviewers were both female and both ethnically black (one West Indian and one African American). Both had several years' prior experience working in Chicago's economically challenged, predominantly African American communities. The interviews took place over the course of one academic year, though we continued making site visits and meeting with teachers and staff over the next year. All interviews were conducted privately, one-on-one, in a closed room (classroom, counselor's room) on the school grounds.

We established a relationship with the school staff early in the summer before the school term commenced and began conducting interviews in late September. Students were recruited by announcement, and parents were recruited through students. Homeroom teachers in the sixth, seventh, and eighth grades gave us the opportunity to describe our study to their students and to invite them and their parents to participate. All participants were offered $\$ 20$ cash compensation for their participation. Parental consent forms were distributed to all students. Those who returned signed consent forms to their teachers were invited to be interviewed. Before the interview commenced, we described the goals of our study. Participants were told that we were conducting a study on how kids make friends at school. Participants were paid in cash at the start of the interview and were reminded that they could decline to answer specific questions or terminate the interview at any time without penalty.

To better establish rapport, and to expand our contextual insights, we spent approximately one-third of our days at the schools over the one-year period during which the bulk of the data was collected. When not conducting interviews, we assisted teaching staff, hung out in classrooms and the schools' social spaces (e.g., the cafeteria, the parking lot, the library, the hallways), and chatted casually with students, parents, and teachers. Students' time at both schools was quite structured. Nevertheless, by these means, we were exposed to incidental opportunities to observe student-student and student-adult interactions in these spaces during school hours. Most of the students at both schools lived a short walk or bus ride away. Occasionally, at the end of the school day, we spent time casually observing students interacting as they walked down the block or took the bus home after school. The continuity and regularity of our presence helped us established rapport with teachers and students, many of whom seemed to become quite comfortable with our presence over the course of the study period. To increase students' comfort during the interview, we did our best to present open, nonthreatening, nonauthoritative demeanors. We smiled and laughed, made jokes and small talk, used casual language, and offered them a choice of candies and chocolate bars to snack on during the conversation.

Most of the students we interviewed appeared comfortable and engaged. Many were verbally and physically animated, open, and smiling at the start of the interview-partly because of the money and candy, partly because the interview meant a break from classwork, and partly because many seemed to feel it a kind of distinction to have their opinions sought after by a friendly adult. Others started off the interview a bit shyly—speaking softly, and smiling and looking away. Eventually, most of the children relaxed, spoke to us easily, laughed openly, and spoke passionately about the peers and teachers who they liked and disliked. Four stu- 
dents seemed bored, distracted, or unforthcoming during the interview. Three of these were eighth grade boys who were performing poorly academically and had reputations for being involved in gangs. The fourth was a sixth grade boy who was on the autism spectrum.

We used a semistructured interview protocol. To increase students' comfort, our interviews moved from less sensitive to more sensitive topics. We began by asking their age, how long they had been at their current school, and what they thought about their current and prior schools and neighborhoods. In the interviews, children detailed the number and nature of their friendships, their routine social activities with friends, and their perceptions of friendship versus more distant forms of peer relations. They recounted how and why their relationships with peers evolved into or out of friendship, and how and friendships were maintained. These discussions often highlighted the entry of new children into classrooms and neighborhoods and sketched mechanisms of mutual adaptation between newcomers and established members of the classroom. In discussion of friendships, children described relationships with a range of peers including classmates, schoolmates, neighbors, and members of their parents' kin and social networks.

Information was also obtained on children's academic ambitions, family background, personal history, and perceptions of their school and neighborhood. Parents and teachers were interviewed about their interactions with and perceptions of the children and the way children chose friends. Although not originally part of our research design or interview protocol, the theme of violence almost immediately came to dominate children's descriptions of their neighborhoods, schools, and friendships.

All interviews were transcribed and coded and recoded several times in increasingly refined categories as we returned to the data to find increasingly refined confirming (and disconfirming) evidence (Glaser and Strauss 1967). The final product is the result of this dialectical process of analysis and reanalysis (Becker 1998). In-depth, open-ended interviews are ideal for questions in which the researcher attempts to understand actors' perceptions of their circumstances, reactions to those perceptions, and ensuing decisions (Lamont 1992; Weiss 1995; Small 2009a). Because our study is based primarily on interviews rather than participant observation, it will generate rich data to meet our objectives: to understand how actors perceive and make decisions about their circumstances. However, we do not provide systematic observational data on interactions among actors. Our approach must eventually be complemented by full ethnographic studies. In addition, because it does not capture the structure of the entire school network (as has been common practice in social network analysis), it can say little about the role of structural conditions in tie formation, except as they are interpreted by actors. In fact, our study aims to fill gaps generated by that already well-saturated perspective.

\section{The Schools}

Brown and Goodwin elementary are neighborhood schools that serve student bodies of similar size with comparable demographic characteristics. Both schools were 
more than 97 percent black, with roughly 95 percent of children eligible for free or reduced lunch. Both schools are located in highly disadvantaged, predominantly African American areas with high rates of violence, with violent crime rates ranging from double to triple the city average. During the study period, Chicago had murder and assault and battery rates of 15 and 602 per year per 100,000 persons. In contrast, Brown's neighborhood had roughly 50 murders, 200 sexual assaults, 1,200 robberies, and 1,880 assaults and batteries per year per 100,000 persons whereas Goodwin's neighborhood had roughly 20 murders, 50 sexual assaults, 500 robberies, and 540 assaults and batteries per year per 100,000 persons. Although Goodwin's neighborhood crime rates were lower than Brown's, Goodwin is sandwiched between two neighborhoods with crime rates that were on par with those at Brown. The violent crime rates in both schools were also high. During the study period, Brown experienced more than 1,300 assaults, 1,400 battery, and 190 weapons incidents per year per 100,000 persons; Goodwin experienced more than 380 assaults and 380 battery incidents per year per 100,000 persons. $^{2}$

\section{Findings}

\section{Perceptions of School and Neighborhood}

The literature on neighborhood conditions has begun to examine more seriously how residents think about and frame the neighborhoods in which they live, based on the idea that framing contributes to social action (Small 2002, 2004; Tach 2009). Consistent with this notion, we asked children to describe their perceptions of both their school and neighborhood. Two patterns emerged. First the most common responses by far centered on the risk of violence and the fear for personal safety. The violence ranged in severity from bullying and scuffles between peers to fights between gangs over territory, victimization by gangs, neighborhood shootings, and altercations between adults involving weapons. ${ }^{3}$ Second, these perceptions reflected their understandings of both their neighborhood and school. Children perceived violence to be pervasive and unpredictable in both settings, and shifting from one to the other did not especially change feelings of safety.

Christina, a shy seventh grader at Brown, described her neighborhood:

I don't go outside around here and I don't think their [my friends'] mothers lets them go outside around here either. Across the street from us there's a family that got into a fight with another family, and an older lady, she went over there with a box cutter and she stabbed the kids. Now she's in jail. After that, I felt more scared than I already was. I really still won't go outside, because I'm scared stuff is going to happen to me.

Kevin at Brown feared attacks from neighborhood gangs: "There's a lot of gangs. If somebody from over here cross the park, they'll get jumped on." Goodwin student Terrance, who was athletic and popular, described how neighborhood gangs 
indiscriminately target young boys:

There's a lot of gangs. It's a lot of Black Disciples, Gangster Disciples, there's a couple more. There's a lot of Gangster Disciple Killers across the track from my grandma's house. The Tre's what's been doing a lot of shooting right here at the gas station. . . . You gotta watch where you walk out here. You can't walk up to that gas station by yourself. You can't go to the park by yourself. Matter of fact, no boys should be over there at all unless they know some people over there. Can't even walk to the library without getting jumped. I walked to the library, I got jumped. Just 'cause I wanted to go read a book I got jumped.

While Christina, Kevin, and Terrance did not get into fights, children who did frequently expressed a fear of being victimized. Jessica at Brown insisted she wanted to avoid fights, yet in the past year she reported being in five fights for which she was disciplined with nine suspension days, one day short of requiring her to attend summer school as punishment. Jessica described the fights as starting with insults ("they called me on my name"). Three fights started as altercations between girls, two with boys. Two fights were one-on-one (between girls), and three of them escalated to ensnare four or more children. In one case, Jessica's brother and her male antagonist's sister from a higher grade "jumped in" to defend their siblings, with Jessica's brother grabbing the boy's sister by the neck to throttle her, and "busting up her lip and nose till it was bleeding."

Jessica explained:

My parents told me you will know if a person is about to hit you. All you got to do is look in their eyes. If a person approach you and they giving you a face; if they walk back up to you, then you've got to punch them out. Let them get away with the first remark, but when they come back in your face, they ready to fight.

Ironically, Jessica's tendency to instigate fights arose from her fear of being caught off-guard in a violent confrontation. Jessica's parents taught her to expect that tense interactions will lead to violence and to act preemptively. ${ }^{4}$

Brandon, who got into school fights about once a year, felt similarly. He explained how fights start at Goodwin:

People might not like people looking at them. So they'll say something, and everybody gets to talking back and forth, and back and forth, and they just end up fighting. The maximum time for you to look at somebody in this school is about four or five seconds. If you look at them and you sit next to one of your friends, they might think that you're talking about them. ${ }^{5}$

In such contexts, children's moodiness, irritability, and a sense of hyperawareness often led to violence. Mrs. Mason, the Goodwin school counselor, described 
Olivia, in the seventh grade:

She got into a lot of conflict. She was always in fights. From talking to her I knew that there was just so much going on at home. She was very sensitive. All you had to do was say the wrong thing, or just anything that sounded like the wrong thing, and she would snap at you. And these kids-they have no tolerance for each other, so they snap back. ${ }^{6}$

Perhaps because children attended school within their neighborhoods, the boundaries between neighborhood and school violence were often blurry. Terrance described how a neighborhood altercation that began with an argument between Carl and Denise led to a scuffle between Carl and William at school, which later escalated into a larger, serious fight in the neighborhood:

Have you heard about how Carl got jumped? It was a lot. He and a boy, William, from another classroom was fighting. Then a whole bunch of William people come in. Carl had one friend, a real good friend with him, Chris. But Chris got knocked down. So now, Carl ain't got nobody with him. While Carl and William was fighting, William's brothers came up from behind and started knocking Carl in the face. Then William's friends came upside, kicking Carl and stuff. Carl tried to run, but he almost got hit by three cars. And Chris; they had to put him on a stretcher. They was fighting because in October, Carl hit William's ex-girlfriend's cousin, Denise, in the lip. It was after school and William wasn't around. Denise was messing with Carl. He kept telling her to leave him alone. Then he punched her up in the mouth. Denise's momma started going crazy. William got real, real mad about that, so they start arguing and stuff. ${ }^{7}$

Carl's story demonstrates not only the permeability of the school-neighborhood boundary but also how costly an isolated aggressive act could be in high-violence environments.

Many of the children reported direct personal exposure to serious violence. One child had a sibling killed, and another had a parent incarcerated because of neighborhood violence. Two children (one boy and one girl) reported being sexually assaulted in their neighborhood park by what they called "raper men." One girl was robbed at gunpoint; another witnessed a stabbing. Several students attended a party where one girl stabbed another. One boy in the eighth grade and one girl's parent were killed in neighborhood violence. Another girl's parents kept her at home for a week and urged her to stay away from windows in the house after an argument with a classmate escalated into violent threats from her family. Six students reported witnessing or participating in serious street fights between groups of youths or adults involving bullets, bats, and box cutters.

As these accounts show, children experienced their neighborhoods and schools as places where violence was pervasive, proximate, and unpredictable in its frequency and severity. Moreover, despite wanting to avoid violence, many children 
engaged in violence at irregular times for a variety of reasons. How do such environments affect the way that children think about friendship?

We found that children reacted to the threat of violence by forming friendships strategically, in a manner designed to minimize two kinds of risk: the risk of being hurt in a physical confrontation and the risk of getting into a confrontation. In what follows, we document five distinct strategies our respondents employed as they formed friendships: protection seeking, cultivating questioners, avoidance, kin reliance, and testing.

\section{Protection Seeking: "Got My Back"}

Many children cultivated friendships that provided physical protection in the event of a fight. The most common narratives about friendship revolved around the idea that friends should "stick up" for or "have [one's] back." Jennifer felt safe thanks to her friends. Because of their protection, she never had problems with bullying or fights. Her friends "don't just hang with you. If somebody bother you, they don't let nothing happen to you; they always got your back." Dennis explained why he chose his two best friends. "I know if somebody walked up to me, and they said they was going jump me, they would be right there to help me." Natasha explained the difference between friends and best friends. "If we're friends, we hang out, we talk. But, [my best friends], they got my back anytime. If something happens, they be defending me. They used to jumping in."

As a new student, Marcus chose his best friends, Tina and Rob, because they shielded him from violence:

When I came here I didn't know anybody. Rob was like, 'Stick around me, ain't nobody goin' to mess with you.' I was like, 'Yeah, okay, nobody ain't goin' to mess with me now.' Tina, she, she sticks up for me a lot. So, I was like, 'Yeah, you is my best friend'. If a dude came over here trying to fight me, they all just be right behind me. So, he would just walk on, get on his jolly way.

Terrance believed that his only "real friend" was an older student who "always had my back." He explained, "When I was in 4th grade, he was in sixth grade. He was cool with everybody so I guess, everybody thought, don't mess with Terrance. I think that was the only real friend I had." Because protection was tightly tied to friendship, children did not expect anyone beyond "real friends" to stand up for them in the face of conflict. Martin explained: "Around here, you'd be lucky for somebody to come in for you [defend you]. That's why people are really lucky to get best friends here."

\section{Avoidance: "I Don't Want Them to Know Me"}

While many children sought protection in response to violence, others avoided investing emotionally in friendships altogether. At some times, this avoidance manifested itself in total isolation; at other times, children cultivated many "associates" but no close friendships. Almost always, children described their reluctance 
to open up to others. The children at Goodwin described Sam as a loner. Because of this, Sam was often the target of taunts, bullying, and accusations that he felt that he was "better than" everyone else. Nevertheless, Sam preferred to remain aloof, a decision he attributed to his past experiences. Sam recalled how naively placing trust in his friends put him in problematic and dangerous situations:

When I was 12, I started messing with the wrong people. They seemed interesting at first, but I didn't know how they really was. Then they started turning out, doing stupid stuff, and I started getting F's. I was starting fights. I was bringing trouble to the school, and I got expelled. There was one person I was with. I got in a car with them, but it was a stolen car. Then we all got locked up. I didn't take nothin', I didn't do nothin', but I got locked up because I was with them. So, after that, I ain't been hanging with them no more. I ain't been trying to make friends. I just be talking to people."

As a result of this and similar experiences, Sam describes a friend as person who helps him avoid trouble: "A friend is a person who won't try to make me do stuff bad stuff, dumb stuff. Like trying to force me to do stuff. Talking about me, if I don't do what they ask me to do, saying I'm a punk, since I'm not doing what they want." Sam is wary of friendship because such relations give peers power to pressure him into delinquent activities that put him in danger.

Neighborhood violence, fights, and entanglements with gangs have become huge preoccupations for Sam. Sam's father moved the family three times in the last four years in search of a safer neighborhood to raise his children. Sam recounted:

Dad keeps on trying to move from all the bad neighborhoods so we could be able to go outside without being killed. The good thing about this neighborhood is a bigger house. The bad thing is just too many gangs shooting and killing each other. You hear a lot of gun shots. I know a couple people who are into that stuff. One time, I saw they was fighting each other. I've gotten into fights before because I didn't wanna do what other kids was telling me to do, like be in a gang with them, and when they was smoking they tried to make me do drugs. We got to arguing, then we end up fighting.

Because of this, Sam interacts only superficially with other children. "Sometimes, I'm talking with some of them, but most of them, I don't. They be with me, but I don't really talk to them, because I don't really like them like that. They just OK, but I don't really like them for a friend or nothing." Sam's experiences have reduced his aspirations for friendship. They have also diminished his willingness to invest affectively in his peers. Although he may have enjoyed his peers' company, he insisted that he "don't really like them like, for a friend or nothing."

Elizabeth's story demonstrates that many children are reluctant to form close emotional relationships with their friends, even when they are, by all appearances, well integrated into friendship networks. Elizabeth was gregarious and widely 
liked for her liveliness and ready smile. She was enthusiastic about extracurricular activities at school, saying "I get to associate with different people, different grades and all that. It's real fun to me." Despite the obvious pleasure that Elizabeth derived from sociability, she revealed that deep down, she was not emotionally invested in her friends. When asked how close she was to her friends, Elizabeth replied:

Not a lot. You know those people I could talk to, I don't want to know. The reason is I don't want them to know me. All they know about me is that I'm 11 and I'm in their class and that's all. I like to keep it that way because I don't like people to know my business, as it could spread.

Elizabeth was wary of admitting even her closest friend, Lynette, into her private life:

I never asked Lynette for her phone number or anything like that. I would prefer her to be at school. I like that, at school, you can be my friend. But, really, I like to be at peace on the weekend. I don't really like to talk to people. I like to be by myself. That's who I kind of am.

Kimberly echoed Elizabeth's guardedness. Kimberly was a skilled ambassador and described herself as "someone for whom everyone is a friend." Kimberly was loved by the teachers, yet popular with her schoolmates, even managing to maintain close friendships with known troublemakers. Kimberly cautiously explained how she balanced these cross-cutting relationships, using the example of Sharon, one of her closest friends but also a girl with a reputation for getting into fights. "Yeah, Sharon. I don't tell her very private things. She's not the type of person you can confide in. I talk to people that are trouble, but, it's what you say to them. You got to watch what you say. If I tell Sharon, she would go tell everybody." Kimberly's wariness to share her private feelings with Sharon or with other girls was directly tied to her concern that sharing her true thoughts would give her friends ammunition to create "drama," which could lead to fights:

Girls cut each other's neck all for nothing. It's drama, like you talk on the phone, be like, "I don't like her," and it's like, "You don't like her?" And then it goes around the school: "She said, she didn't like you," and they keep up the drama like that. I got only a couple of real friends, but, I talk to everybody. I'm cool with everybody; I don't have no problems with nobody.

\section{Testing: "I Watch People Closely Before I Try to Be Friends with Them"}

The children we interviewed believed that friendships had to be negotiated strategically. Many selected their friends after careful observation. Often, children created "tests" to assess the trustworthiness of potential friends. Michael shared advice on 
choosing friends: "Keep a close eye on the people that you might think you want to hang out with, because I feel that you need to know a person very good before you socialize with them. I watch people closely before I try to really engage and be close friends with them." Ruby employed "testing periods" to reduce uncertainty about whom to trust. Popular and talkative Ruby described her approach to friendship: "I observe people a lot. I watch them, see what their actions are. I could just look at you for a long time. Then I decide which friends I want to hang out with or not." Alice watched her potential friends carefully "to see if they are true friends or would they go behind your back, stoop low, and to see whether they tell stuff about you that's not true. I'd be testing people. I'd tell somebody something that's not true, but then if somebody else hears what I told that person, I know that they're not a true friend."

Sandra had developed her wariness towards her peers through close observation:

I learned just from watching. Just look. Watch them. [You] start knowing that you really don't need many friends. You have friends but don't let them in too close, unless you've been with them forever. Somebody you just met two years ago, nn-mm [no], don't let them in too close. Because people, when you let them in, that's when you start feeling like you getting married. That one year or so after you get married, they all normal like they used to be. But then, like, a year later, they start showing the real side. That's how it's like.

By invoking an analogy of marital betrayal, Sandra draws on cultural scripts in some disadvantaged communities that portray romantic partners as routinely willing to exploit each other for personal gain (e.g., Liebow 1967:89-104; Harding 2010:162-203). Sandra's distrust of her potential friends is consistent with other researchers' reports of distrust among social intimates in disadvantaged communities (Smith 2007; Ray 2016).

Kimberly, whom we saw before, was also suspicious. She explained:

You got to ease it out. First you got to find out if your friend real or fake. This is what some people do. They say, "I don't like her really." If they tell, then they not real friends. They just be like your "hey, or bye," associates. But, if they keep it between me and you, they cool. Then you start walking home together, and calling each other, spending time with each other, and that's how you become best friends.

For Kimberly, most of her peers were "hey or bye" associates: they were good for sociability, but did not earn her trust.

\section{Cultivating Questioners: "Just Let It Go"}

Anderson (1999), Jones (2004), and others have argued that, in contexts of violence, both men and women face a street code wherein signs of disrespect must be quashed. 
In many cases, actors resort to violence in order to defend their reputations. Still, most actors are reluctant to engage in violence, because its consequences are costly, messy, and unpredictable (Collins 2011). Violence often escalates when an audience observes and comments on a show of disrespect and when the target of the attack is unable to find a face-saving alternative to violence (Papachristos 2009; Skogan et al. 2009).

In violent contexts, "quick wits and quick fists confer status" (Papachristos 2009:79). In such environments, early warning about public insults gives individuals time to develop face-saving strategies that reduce the mandate to protect their reputations through physical violence. The children in our study exhibited friendship patterns that were shaped by these dynamics. Children described how they used friendships to help them forge face-saving, nonviolent responses to reputational threats. They did so by choosing friends who would engage in what we call reputational repair work. Children selected friends who were skilled at neutralizing insults made about them in their absence, who informed them about others' insults, who publicly discouraged them from escalating arguments, and who publicly coaxed them away from physical fights.

Despite being teased repeatedly by other classmates about his large eyes, Dennis had never been in a fight. Dennis credited this fact to his friends, on whom he depended to forestall conflict on his behalf, first by counteracting insults made against him and, when necessary, by helping him reframe the significance of insults to his reputation. "If a rumor is going around [about me], they would ask the person to stop, then tell them to stop. They'll say 'Man, it's not cool.' If the person won't listen, then they'd tell me and say, 'Just let it go by."' In this example, Dennis's friends often engaged in two kinds of reputational repair on his behalf. They would attempt to nip insulting rumors about him in the bud. When rumors became common knowledge, they publicly encouraged Dennis to "let it go by." In so doing, they gave Dennis a face-saving pathway out of a potential confrontation. Dennis could walk away from the insult and still look like the bigger person. His friends helped him avoid conflicts over trivial comments without serious damage to his reputation.

Like Dennis, Tracey believed that coaxing her friends away from fights was the central duty of a friend. Tracey was soft-spoken and studious and came from one of the neighborhood's poorer families. Tracey's classmates made fun of her often, calling her dark skin "crispy," her short hair "bald," and her clothing "old" and "dirty." Tracey's small group of friends was similarly disadvantaged. They were labeled "lames," frequently teased, and shunned in the school's common spaces. Still, Tracey discouraged her friends from fighting and expected her friends to do the same for her in return. "I tell my friends don't fight for this and that. My sister was about to fight this girl because she said something to her in the bathroom. I was like nuh-uh [no], don't do it. It's going to go on your record." Although Tracey could not counter the insults directed at herself and her friends, she nevertheless reframed the severity of the insults by recalling the cost of having a blemished school record.

Jennifer showed creative skill at reputational repair when she described how she dissuaded her best friend Tamara from fighting their mutual tormentors who 
tried to provoke them over a two month period:

I said, "They just got an attitude problem. They want to fight but I'm not going to fight unless it's really, really, really something, not for none of this nonsense stuff, like arguin' over he said, she said. Like, 'She told me that you was talking about me. He told me you was talking about me.' If you won't tell me to my face, then that's it. I'm not going to argue. If it's not something serious, real serious, I'm not going to fight you. But if you really bother me for a long, long time, and you really be pushing me to fight you, then I'm going to fight you."

Jennifer and Tamara were taunted for two months. While Tamara originally saw these insults as threats to her and Jennifer's reputations, Jennifer reframed them as their tormentors' "attitude problem." Jennifer also de-escalated the severity of the problem by insisting that the insults were "not serious." For Jennifer, an insult is serious only if it is "to my face" and "if it's been persisting for a long, long time." By publicly re-framing the severity of the problem, Jennifer helped steer her friend away from a fight in way that saved face.

\section{Kin Reliance: "You Want to Be Close to Your Family, Just in Case"}

Many of the children turned to kin to buffer them from violence and to fulfill the emotional and companionship needs that friendships ordinarily provide. Tracey described how dependence on peer-age kin kept her from transferring from Goodwin to a school with better academic opportunities:

I don't know how I would ever survive. You want to be close to your family, just in case anything happens. You might need them for something and they won't be there. If there was like a fight and you might get jumped on, they would help you not fight but cool it down. Instead of fighting just talk it out to solve the problem. Like that.

Tracey revealed the responsibility of protection that is associated with kinrelations through an incident in which she intervened to defend a reputational attack on her cousin:

We was walking and Kenny said something about my cousin. Him and my cousin always getting into it. I said "If you don't like her, say something about it to me, don't tell everybody else." Don't talk about my cousins 'cause that's my responsibility. If you're going to say stuff about my cousins I gotta say something back to you cause if I don't, and word get back to my momma, I'm going to get in trouble for not defending my cousin.

By asking Kenny to just "say something to me," Tracey reduced the pressure on her cousin to escalate his rivalry with Kenny into a fight. 
Sam relied only on kin for companionship. When asked who he relied on, Sam responded:

My family. That's it. I ain't never wanted a best friend. I just talk to people. I don't try to make friends with them. I just talk to them. 'Cause I don't know if they real friends or not. A real friend is a person who won't try to get you to be in a gang and stuff like that, who won't try to get you into trouble with the stuff they doing. So, I don't try to make friends with nobody, I just talk to them. I don't know how they is. I don't really trying to be no friends with nobody.

For these children, family networks imply safety and unquestioned loyalty.

The idea that kin networks are one of the few reliable ways to secure one's safety in violent neighborhoods was strongly held among both adults and children in our field sites. Children related that their parents often chose to send them to particular schools because they already had cousins or fictive kin there. Kin reliance has long been a crucial survival strategy in low-income African American communities (Stack 1974). The tendency of the children in our study to rely on kin for physical and reputational protection echoes similar findings by Jones (2004) among young adults negotiating their communities' dangerous streets.

The interlocking relationship between friendship and family, the tendency to only trust family, and the high bar that others must pass to meet the threshold of true friendship are illustrated in 12-year-old Monica's story. Monica felt betrayed in the past by peers who called themselves her friends: "[They] talk about me, like, 'Oh, Monica, you fat, you ugly, you dirty.' They say all kinds of stuff. But then they want to be my friend when the credit card comes out. They wanna be my friend when they see that I got stuff." Monica had no best friends in school:

Best friend ... I have girl friends, I can't say best friends. A best friend is somebody I can depend on. When I need you I can call you, and you come out here to see what's wrong. That's a best friend. A best friend, when I'm down and I'm out, I might not have money and stuff to eat. I know if I call you, you'll have my back. You'll have some money for me to eat, you'll be right there. And a good friend to me is: I can depend on you for certain things, but not everything. And, I could trust you, most of the time, but not all of the time.

Monica's only "true friend" was an 18-year-old near-relative:

There might be one friend that I treat differently, and that's the girl that I always used to live with. We grew up together. Her brother's my sister's baby's daddy. We got a real close connection, because I know how she is, now, I know what she's like. I know everything about her. It's so deep that I call her family —-that's my friend. 
Monica had learned from experience that friends could sometimes be trusted for smaller things but that only family and fictive kin could truly be trusted.

\section{Multiple Strategies}

As we have seen, the responses of the children were anything but singular. Jennifer and Dennis sought friends who could protect them but also cultivated friendships with people who could help them avoid violence and negotiate the boundaries between violence and respect. Tracey and Tamara cultivated such questioners, too, but also turned to trusted kin members, rather than nonkin peers, when thinking of whom to consider their closest friends. Sam seemed to embody the classic distrustavoidance perspective but also relied substantially on his own kin for friendships. Kimberly revealed evidence of the distrust-avoidance pattern, but rather than merely avoiding others altogether, she cultivated friendly relationships with everyone, including children like Sharon, who had reputations as troublemakers and fearless fighters.

In fact, though space considerations limited how much of our respondents' statements could be reported, most of the children described above reported using two or more strategies. Michael tested and befriended questioners; Terrance sought protectors and questioners; Sandra and Alice engaged in avoidance, kin-reliance and testing; Ruby avoided and tested; Christina avoided and relied on kin; and Natasha engaged in avoidance and testing while cultivating protectors and questioners. More than half of the children we interviewed used several strategies to choose and form friendships. The pervasiveness of multiple strategies among the children we interviewed is particularly notable given that our study was not originally designed to explicitly probe for multiple strategies. Children do not just seek protection or avoid others; they engage in multiple, highly deliberative strategies.

\section{Conclusions}

We have shown that sixth, seventh, and eighth graders in two Chicago schools responded actively to the violence in their communities by adopting a strategic and instrumental attitude toward friendship that involved multiple strategies: seeking friendships for protection, avoiding emotional investment in friendship, cultivating friends who helped them avoid violence, testing friends to ensure their worthiness, and relying on kin or fictive kin to fulfill their emotional needs for friendship. Their closest friends were those who not only protected them in the event of violence but also helped them manage peer relations and their social status in ways that minimized the chances of violent escalation.

Our findings help fill several gaps in the literature. First, we document a far more strategic approach to friendship formation among children than reported in the traditional literature on children's friendship networks. We propose that the proximate, pervasive, and unpredictable nature of violence made the latter a master frame through which these children organized friendship choices. Pervasive and proximate neighborhood violence may overwhelm other structural conditions, 
forcing children to think strategically first and in light of affective interests later. The notion that traditional processes such as homophily may operate differently in different contexts of interaction contributes to the recent body of work that attempts to understand how networks are affected by the context of interaction (Mollenhorst, Völker, and Flap 2008; Small 2009b; Doreian and Conti 2012). Homophily of attitudes or hobbies may matter less than homophily of other kinds, such as attitudes toward violence, and factors other than homophily may turn out to be more important. While we have identified far more strategic and instrumental attitudes than reported in work outside of violent contexts, systematically comparative work is needed. It could be the case that violence creates a strategic approach that would otherwise not be present, that it heightens the level of always-present strategic thinking, or that in contexts where there is no violence, children are simply strategic about other things. Our reading of the literature suggests the first or second of these, but only comparative work can tell. Future work should examine the extent to which presumably universal processes depend on the conditions in which friendship formation and network studies have traditionally been conducted.

Second, our findings offer reason to revise the traditional notion that the way young people respond to violence is merely to withdraw or join gangs for protection. While withdrawal and protection seeking were important, other strategies-such as using others to help negotiate violence or sidestep it-were equally prevalent. In effect, we suggest that one consequence of violence is the very heterogeneity of strategies deployed. ${ }^{8}$ Children were forced to be maximally strategic, and therefore highly adaptable, in their decision-making because no strategy was fool-proof and the threats of the context itself were dynamic. For example, while protection seeking and kin reliance provided defense in fights, they also committed children to reciprocally defend peers and kin. Similarly, while avoidance freed children from becoming tangled in others' fights, it left them easy targets for bullies and other aggressive peers seeking to improve their reputations for "toughness" by picking fights with or beating up on lone kids. ${ }^{9}$ The children we interviewed were immersed in environments that forced them to continuously evaluate and revise their strategies to avoid violence. Rooting the analysis deeply in an understanding of people's decision-making processes becomes essential to understand networks and survival in such contexts (Small forthcoming).

Third, these findings broaden our understanding of how neighborhood conditions may affect children (Sampson et al. 2002; Chetty et al. 2016). Much of the research on neighborhood effects has shifted attention to understanding the mechanisms that link neighborhood poverty and disadvantage to unwanted outcomes. The core neighborhood condition the children we interviewed responded to was pervasive, proximate, and unpredictable violence. Their response was a notably strategic approach to friendship formation in ages as young as 11 , a set of strategies likely to have long-term consequences for trust, prosocial behavior, and interpersonal relations. In fact, given these conditions, it is not surprising that studies of social networks of adults in disadvantaged neighborhoods have reported high levels of distrust (Smith 2007). Distrust may result not from neighborhood poverty as such but from early exposure to interpersonal violence and the tragically strategic responses children are forced to develop. The effects of violence on how 
children learn to relate to others may be one of the core mechanisms through which neighborhoods affect social relationships among adults.

\section{Notes}

1 The original intent of the larger project was to compare children in a high-mobility and a low-mobility school that were otherwise similar. To our surprise, children in both schools were deploying nearly identical friendship formation practices. Further, the practices were tied to an issue we did not originally anticipate: a strong sensitivity to the high levels of violence.

2 The rates of violent crime in the neighborhoods we studied are very similar to the crime rates in Franklin and Roxbury Crossing, the violent neighborhoods from which Harding (2010) drew his low-income sample. However, in our study, the homicide rate in Brown's neighborhood was twice that of Franklin's, Harding's most violent neighborhood.

3 Typically, fights between peers began with name-calling and shoving and escalated to involve kicking, slapping, scratching, hair-pulling, punching, stomping, and pummeling. Fights often drew blood. In most cases, fights would start off between two children and escalate to involve multiple peers. In a significant minority of cases, fights involved weapons (knives, box cutters, guns with rubber bullets) and resulted in serious injury, requiring ambulances and brief hospitalization.

4 Harding (2010:65) also found that parents try to prepare adolescent boys to cope with neighborhood violence by counseling them on how and when to fight.

5 Harding (2010:47-52, 73) and Paulle (2013:xiv, 144-5, 157-8) also found that violent confrontations between teenagers is readily triggered by perceived insults and "dirty" looks in high-poverty, high-violence contexts. Because they must navigate an environment in which otherwise harmless verbal jousting or a simple glance could have dire, even deadly, consequences, adolescents in these communities often engage in rigorous self-monitoring (e.g., studiously avoiding eye contact, avoiding stray remarks that could be misinterpreted, etc.).

6 In a compelling six-year ethnographic study, Paulle (2013:67-104) documents the ways that the deprivations, indignities, chronic stress, and instability of life in highly disadvantaged urban communities leave adolescents in severely depleted, conflicted, and highly emotionally reactive states that prime them to engage in forms of violent and selfdestructive behavior that they reject in their calmer moments. Like Paulle's (2013:1-32) subjects, the children in our study struggle with life in troubled, economically unstable homes and neighborhoods and schools where bouts of unpredictable, lethal violence frequently punctuate a constant, oppressive atmosphere of lower-level threats, aggression, and intimidation; they must use their often-depleted powers of self-control to restrain emotional surges that arise out of fear and pent-up frustration.

7 William was also in a gang.

8 Our findings differ from work that uncovered gender differences in risk-management strategies among teenagers in violent neighborhoods (Cobbina et al. 2008). The difference may be due to age grading. Cobbina et al.'s respondents had an average age of 16, whereas our respondents had an average age of 13 . For numerous reasons, teenagers might experience gendered risks differently from children just entering adolescence.

9 Paulle (2012:41-68) provides numerous examples of high schoolers beating up on lowerstatus students to shore up their "street" reputations. Harding $(2010: 39,77)$ shows how teens who engage in what we call "avoidance" fail to participate in the system of mutual 
obligations that "protection seeking" provides, leaving them without help when they are targeted by peers spoiling for a fight.

\section{References}

Anderson, Elijah. 1990. Streetwise. Chicago: University of Chicago Press.

Bell, Carl C., and Esther Jenkins. 1993. "Community Violence and Children on the South Side of Chicago." Psychiatry: Interpersonal and Biological Process 56:46-54. https://doi .org/10 . 1080/00332747.1993.11024620

Bostman, Julie, and Mitch Smith. 2016. "As Chicago Murder Rate Spikes, Many Fear Violence Has Become Normalized." The New York Times December 28, 2016.

Brown, Bradford. 1989. "The Role of Peer Groups in Adolescents' Adjustment to Secondary School." Pp. 188-215 in Peer Relationships in Child Development, edited by T. J. Berndt and G. W. Ladd. New York: Wiley.

Chetty, Raj, Nathaniel Hendren, and Lawrence F. Katz. 2016. "The Effects of Exposure to Better Neighborhoods on Children: New Evidence From the Moving to Opportunity Experiment." American Economic Review 106(4):855-902. https : //doi . org/10.1257/aer . 20150572

Cobbina, Jennifer, Jody Miller, and Rid K. Brunson. 2008. "Gender, Neighborhood Danger, and Risk-Avoidance Strategies among Urban African-American Youths." Criminology 46 673-709. https://doi.org/10.1111/j.1745-9125.2008.00122.x

Collins, Randall. 2011. "C-Escalation and D-Escalation: a Theory of the Time-Dynamics of Conflict." American Sociological Review 77(1) 1-20. https://doi.org/10.1177/ 0003122411428221

Coughlin, Brenda C., and Sudhir A. Venkatesh. 2003. "The Urban Street Gang after 1970." Annual Review of Sociology 29:41-64. https : //doi . org/10.1146/annurev . soc . 29.101602. 130751

Crosnoe, Robert, Kenneth A. Frank, and Anna S. Mueller. 2008. "Gender, Body Size and Social Relations in American High Schools." Social Forces 86 (3): 1189-1216. https: //doi.org/10.1353/sof.0.0004

Doreian, Patrick, and Norman Conti. 2012 "Social Context, Spatial Structure and Social Network Structure." Social Networks 34(1):32-46. https://doi .org/10.1016/j . socnet. 2010.09 .002

Eder, Donna, and Maureen T. Hallinan. 1978. "Sex Differences in Children's Friendships." American Sociological Review 43:237-250. https: //doi .org/10.2307/2094701

Emirbayer, Mustafa, and Jeff Goodwin. 1994. "Network Analysis, Culture, and the Problem of Agency." American Journal of Sociology 99:1411-54. https : //doi . org/10 . 1086/230450

Emirbayer, Mustafa, and Ann Mische. 1998. "What Is Agency?" American Journal of Sociology 103:962-1023. https://doi.org/10.1086/231294

Epstein, Joyce. 1983. "Examining Theories of Adolescent Friendship." Pp.39-61 in Friends in School, edited by Joyce L. Epstein and Nancy Karweit. San Diego: Academic Press. https://doi.org/10.1016/B978-0-12-240540-2.50009-8

Finkelhor, David, Rirchard Ormrod, Heather Turner, and Sherry L. Hamby. 2005. "The Victimization of Children and Youth: a Comprehensive, National Survey." Child Maltreatment 10(1):5-25. https : //doi.org/10.1177/1077559504271287 
Finkelhor, David, Heather Turner, Sherry L. Hamby, and Richard Ormrod. 2011 Polyvictimization. University of New Hampshire: Crimes against Children Research Center.

Finkelhor, David, Anne Shattuck, Heather Turner, and Sherry L. Hamby. 2014 "Trends in Children's Exposure to Violence, 2003-2011." JAMA Pediatrics 169(8):746-54. https : //doi.org/10.1001/jamapediatrics.2015.0676

Flores-Gonzalez, Nilda. 2002 School kids/Street Kids. New York: Teachers College Press.

Frank, Kenneth A., Chandra Muller, and Anna S. Mueller. 2013. "The Embeddedness of Adolescent Friendship Nominations: the Formation of Social Capital in Emergent Network Structures." American Journal of Sociology 119(1):216-53. https : //doi .org/10. $1086 / 672081$

Furman, Wyndol, Valerie A. Simon, Laura Shaffer, and Heather Bouchey. 2002. "Adolescents' Working Models and Styles for Relationships with Parents, Friends, and Romantic Partners." Child Development 73:241-55. https ://doi .org/10.1111/1467-8624.00403

Garofalo, James. 1981. "The Fear of Crime - Causes and Consequences." Journal of Criminal Law and Criminology 72:839-57. https: //doi .org/10.2307/1143018

Gifford-Smith, Mary E., and Celia A. Brownell. 2003. "Childhood Peer Relationships: Social Acceptance, Friendships, and Peer Networks." Journal of School Psychology 41:235-84. https://doi.org/10.1016/S0022-4405(03)00048-7

Giordano, Peggy C. 2003. "Relationships in Adolescence." Annual Review of Sociology 29:257-81. https://doi.org/10.1146/annurev.soc.29.010202.100047

Glaser, Barney, and Anselm L. Strauss. 1967. The Discovery of Grounded Theory. Chicago, Aldine Publishing Company.

Goodreau, Steven M., James A. Kitts, and Martina Morris. 2009. "Birds of a Feather, or Friend of a Friend? Using Exponential Random Graph Models to Investigate Adolescent Social Networks." Demography 46(1):103-25. https ://doi .org/10.1353/dem.0.0045

Hafen, Christopher A., Beth Laursen, and Dawn Delay. 2012 "Transformations in Friend Relationships across the Transition into Adolescence." Pp. 69-90 in Relationship Pathways, edited by Brett Laursen and Andrew Collins. Thousand Oaks, CA: Sage. https: //doi.org/10.4135/9781452240565.n4

Hallinan, Maureen T. 1976 "Friendship Patterns in Open and Traditional Classrooms." Sociology of Education 49(4):254-265. https : //doi . org/10.2307/2112312

Hallinan, Maureen T., and Nancy Tuma. 1978 "Classroom Effects on Change in Children's Friendships." Sociology of Education 51(4):270-282. https://doi .org/10.2307/2112365

Hallinan, Maureen T., and Edwin E. Hutchins. 1980. "Structural Effects on Dyadic Change." Social Forces 59(1): 225-245. https ://doi .org/10.2307/2577842

Hallinan, Maureen T. 1979. "Structural Effects on Children's Friendships and Cliques." Social Psychology Quarterly 42 (1):43-54. https : //doi .org/10.2307/3033872

Harding, David. 2009. "Violence, Older Peers, and the Socialization of Adolescent Boys." In. American Sociological Review 74:445-64. https://doi .org/10.1177/000312240907400306

Harding, David. 2010. Living the Drama. Chicago: University of Chicago Press. https: //doi.org/10.7208/chicago/9780226316666.001.0001

Hartup, Willard W. 1996. "The Company they Keep: Friendships and their Developmental Significance." Child Development 67:1-13. https://doi .org/10.2307/1131681

Haselager, Gerbert J.T., Willard W. Hartup, Corenlis F.M. VanLieshout, and J. Marianne A. Riksen-Walraven. 1998. "Similarities between Friends and Non-Friends in Middle 
Childhood." Child Development 69:1198-1208. https://doi .org/10.1111/j.1467-8624 . 1998.tb06167.x

Jones, Nikki. 2004. "'It's Not Where You Live, It's How You Live': How Young Women Negotiate Conflict and Violence in the Inner City." Annals of the American Academy of Political and Social Science 595:49-62. https://doi .org/10.1177/0002716204267394

Jones, Nikki. 2009. Between Good and Ghetto. Newark, NJ: Rutgers University Press.

Kandel, Denise B. 1978. "Homophily, Selection and Socialization in Adolescent Friendships." American Journal of Sociology 84:427-36. https: //doi .org/10.1086/226792

Lamont, Michele. 1992. Money, Morals and Manners. Chicago: University of Chicago Press. https://doi.org/10.7208/chicago/9780226922591.001.0001

Lazarsfeld Paul, and Robert Merton. 1954. "Friendship as a Social Process: a Substantive and Methodological Analysis." Pp. 18-66 in Freedom and Control in Modern Society, edited by Morroe Berger, Theodore Abel, and Charles H. Page C. New York: Van Nostrand.

Liebow, Elliot. 1967 Tally's Corner. New York, Little, Brown.

Lubbers, Miranda, and Tom Snijders. 2007. "A Comparison of Various Specifications of the Exponential Random Graph Model: A Reanalysis of 102 Student Networks in School Classes." Social Networks 29:489-507. https://doi.org/10.1016/j. socnet.2007.03. 002

McFarland, Daniel, James Moody, David Diehl, Jeffrey Smith, and Reuben J. Thomas. 2014. "Network Ecology and Adolescent Social Structure." American Sociological Review 79(6):1088-1121. https://doi.org/10.1177/0003122414554001

McIntyre, Jennie. 1967. "Public Attitudes toward Crime and Law Enforcement." Annals of the American Academy of Political and Social Science 374:34-46. https://doi .org/10.1177/ 000271626737400104

McPherson, Miller, Lynn Smith-Lovin, and James M. Cook. 2001. "Birds of a Feather: Homophily in Social Networks." Annual Review of Sociology 27:415-44. https : //doi .org/ 10.1146/annurev.soc.27.1.415

Miller, Jody. 2000. One of the Guys? New York: Oxford University Press

Mollenhorst, Gerald, Beate Völker, and Henk Flap. 2008 "Social Contexts and Personal Relationships: the Effect of Meeting Opportunities on Similarity for Relationships of Different Strength." Social Networks 30(1):60-8. https://doi.org/10.1016/j.socnet. 2007.07 .003

Moody, James. 2001. "Race, School Integration, and Friendship Segregation in America." American Journal of Sociology 107(3):679-716. https : //doi . org/10 . 1086/338954

Ness, Cindy D. 2010. Why Girls Fight. New York: NYU Press. https ://doi .org/10.18574/ nyu/9780814758403.001.0001

Papachristos, Andrew. 2009. "Murder by Structure: Dominance Relations and the Social Structure of Gang Homicide." American Journal of Sociology 115 74-128. https://doi. org/10.1086/597791

Parker, Jeffrey G., and Steven R. Asher. 1987. "Peer Relations and Later Personal Adjustment: Are Low Accepted Children at Risk?" Psychological Bulletin 102:357-89. https://doi . org/10.1037/0033-2909.102.3.357

Parker, Jeffrey G., and John Seal. 1996. "Forming, Losing, Renewing, and Replacing Friendships: Applying Temporal Parameters to the Assessment of Children's Friendship Experiences." Child Development. 67:2248-2268. https://doi.org/10.2307/1131621

Paulle, Bowen. 2013 Toxic Schools. Chicago: University of Chicago Press. https://doi .org/ $10.7208 /$ chicago/9780226066554.001.0001 
Peterson, Dana 2011. "Girlfriends, Gun-Holders, and Ghetto-Rats? Moving Beyond Narrow Views of Girls in Gangs." Pp 71-84 in Delinquent Girls, edited by Shari Miller, Leslie D. Leve, and Patricia K. Kerig. New York: Springer.

Pyrooz, David C., and Gary Sweeten. 2015. "Gang Membership between Ages 5 and 17 Years in the United States." Journal of Adolescent Health. 56(4):414-19. https: //doi .org/ 10.1016/j · jadohealth.2014.11.018

Rambaran, J. Ashwin, Jan Kornelis Dijkstra, Anke Munniksma, and Antonius H.N. Cillessen. 2015. "The Development of Adolescents' Friendships and Antipathies: a Longitudinal Multivariate Network Test of Balance Theory." Social Networks 43:162-76. https ://doi. org/10.1016/j.socnet.2015.05.003

Ray, Ranita. 2016 "Exchange and Intimacy in the Inner City: Rethinking Kinship Ties of the Urban Poor." Journal of Contemporary Ethnography 45(3) 343-64. https : //doi .org/10. $1177 / 0891241614568191$

Rector, Kevin. 2016. "Deadliest Year in Baltimore History Ends with 344 Homicides." Baltimore Sun, January 1, 2016.

Ritter, Nancy, Thomas R. Simon, and Reshmar R. Mahendra. 2014. "Changing Course: Keeping Kids Out of Gangs." NIJ Journal 273 (2014): 16-27.

Rubin, Kenneth H., David Lynch, Robert Coplan, Linda Rose-Krasnor, and Cathryn L. Booth. 1994 "Birds of a Feather: Behavioral Concordances and Preferential Personal Attraction in Children." Child Development 65:1778-85. https ://doi .org/10.2307/1131293

Rude, Jesse, and Daniel Herda. 2010. "Best Friends Forever? Race and the Stability of Adolescent Friendships." Social Forces 89(2): 585-607. https://doi.org/10.1353/sof . 2010.0059

Sampson, Robert, Jeffrey Morenoff, and Thomas Gannon-Rowley. 2002. "Assessing Neighborhood Effects: Social Processes and New Directions." Annual Review of Sociology 28:443-78. https://doi.org/10.1146/annurev.soc.28.110601.141114

Sanchez-Jankowski, Martin. 1991. Islands in the Street. Berkeley: University of California Press.

Shrum, Wesley, Neil H. Cheek, and Saundra M. Hunter. 1988. "Friendship in School: Gender and Racial Homophily." Sociology of Education 61:227-239. https: //doi .org/10. 2307/ 2112441

Skogan, Wesley G., Susan M. Hartnett, Natalie Bump, and Jill Dubois. 2009. Evaluation of Ceasefire-Chicago. United States Department of Justice.

Small, Mario L. 2002. "Culture, Cohorts, and Social Organization Theory: Understanding Local Participation in a Latino Housing Project." American Journal of Sociology 108:1-54. https://doi.org/10.1086/345649

Small, Mario L. 2004. Villa Victoria. Chicago: University of Chicago Press. https: //doi .org/ 10.7208/chicago/9780226762937.001.0001

Small, Mario L. 2009a. "How Many Cases Do I Need? On Science and the Logic of Case Selection in Field Based Research." Ethnography 10:5-38. https://doi.org/10.1177/ 1466138108099586

Small, Mario L. 2009b. Unanticipated Gains. New York: Oxford University Press. https: //doi.org/10.1093/acprof : oso/9780195384352.001.0001

Small, Mario L. Forthcoming. Someone To Talk To. New York: Oxford University Press.

Smith, Sandra S. 2007. Lone Pursuit. New York: Russell Sage Foundation.

Stack, Carol. 1974. All Our Kin. Basic Books. 
Tach, Laura. 2009. "More than Bricks and Mortar: Neighborhood Frames, Social Processes, and the Mixed-Income Redevelopment of a Public Housing Project." City and Community 8(3):273-303. https://doi .org/10.1111/j.1540-6040.2009.01289.x

Thrasher, Frederic. [1927] 2013. The Gang. Chicago: University of Chicago Press.

Tuma, Nancy, and Maureen T. Hallinan. 1979. "The Effects of Sex, Race, and Achievement on Schoolchildren's Friendships" Social Forces 57(4): 1265-1285. https ://doi .org/10. 2307/ 2577270

Vaquera, Elizabeth, and Grace Kao. 2008 "Do You Like Me as Much as I Like You? Friendship Reciprocity and Its Effects on School Outcomes among Adolescents." Social Science Research 37(1):55-72. https://doi .org/10.1016/j.ssresearch.2006.11.002

Venkatesh, Sudhir A. 2000. American Project. Harvard University Press

Verbrugge, Lois. 1977. "The Structure of Adult Friendship Choices." Social Forces 56:576-97. https://doi.org/10.2307/2577741

Walker-Barnes, Chanequa J., and Craig Mason. 2001. "Perceptions of Risk Factors for Female Gang Involvement among African American and Hispanic Women." Youth and Society 32:303-36. https://doi.org/10.1177/0044118X01032003002

Weiss, Robert. 1995. Learning from Strangers. New York: Free Press.

Acknowledgements: This research was supported by the MacArthur Foundation, the University of Chicago, the National Opinion Research Center, and Harvard University. We thank Karen Davis and Lara Perez-Felkner for fieldwork, interview work, and other research assistance instrumental to this project and David Harding for comments and criticisms. Direct correspondence to Mario L. Small, 33 Kirkland St, Department of Sociology, Cambridge, MA 02138 or mariosmall@fas.harvard.edu.

Anjanette M. Chan Tack: Department of Sociology, University of Chicago. E-mail: amc75@uchicago.edu.

Mario L. Small: Department of Sociology, Harvard University.

E-mail: mariosmall@fas.harvard.edu. 